\title{
IMPLEMENTATION OF DIASTASIS EXERCISE ON ABDOMINAL RECTI DIASTASIS DEGREE AMONG POST-PARTUM MOTHERS
}

\author{
Rizki Amalia, Elly Dwi Masitha \\ Faculty of Nursing and Midwifery, Universitas Nahdlatul Ulama Surabaya
}

\begin{abstract}
Background: Diastasis recti, or rectus abdominis diastasis, is defined as a gap of about $2.7 \mathrm{~cm}$ or greater between the two sides of the rectus abdominis muscle. Diastasis recti is very common during and following pregnancy. This is because the uterus stretches the muscles in the abdomen to accommodate the growing baby. This study aimed to analyses the implementation of diastasis exercise on abdominal recti diastasis degree among post-partum mothers.

Subjects and Method: This was a randomized control trial conducted at a midwife's practice. A total of 63 postpartum mothers was selected for this study and randomly allocated into two groups: 33 mothers in the diastasis exercise group and 30 mothers in the control group. The independent variable was diastasis exercise. The dependent variable was the degree of abdominal rectification diastasis. The data were collected using questionnaire and observation. The data were analyzed by chi-square.

Results: A total 63 postpartum mothers were investigated, consisting of 34 multiparous and 29 primiparous mothers. Ten of 33 (30.3\%) of postpartum mothers in the diastasis exercise group experienced unfit degree of abdominal rectification diastasis. Ten of 30 (33.3\%) of postpartum mothers in the control group experienced unfit degree of abdominal rectification diastasis. This difference was not statistically significant.

Conclusion: Diastasis exercise does not show effectiveness in recovering normal abdominal diastasis.
\end{abstract}

Keywords: postnatal period, diastasis recti, diastasis exercise

\section{Correspondence:}

Rizki Amalia. Faculty of Nursing and Midwifery, Universitas Nahdlatul Ulama Surabaya, West Java, Indonesia. Jl. Smea No 57 Wonokromo. Email: amalia24@unusa.ac.id. Mobile: 085655581002

The $6^{\text {th }}$ International Conference on Public Health Best Western Premier Hotel, Solo, Indonesia, October 23-24, 2019 | 201 